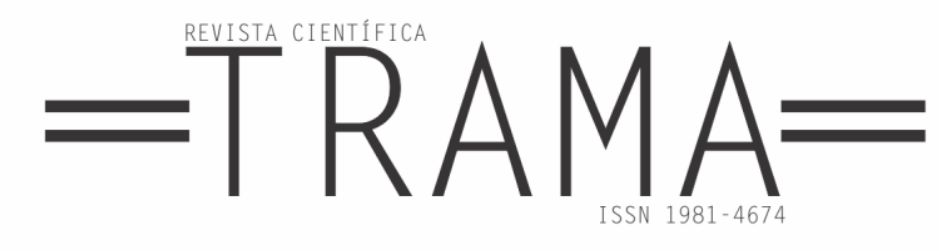

\title{
EsCOlHAS LEXICAIS NO PROCESSO DE TRADUÇÃO DO PORTUGUÊS ESCRITO PARA A LÍNGUA DE SINAIS
}

\author{
Eliziane Manosso STREIECHEN ${ }^{1}$ \\ Josiane de Jesus OLIVEIRA ${ }^{2}$
}

\begin{abstract}
Resumo: $O$ presente ensaio tem como objetivo analisar as escolhas lexicais $e$ estratégias adotadas para traduzir um texto escrito na Língua Portuguesa (LP) para a Lingua Brasileira de Sinais (Libras). Tratase de uma pesquisa qualitativa de caráter exploratório, a qual consiste na análise do corpus - vídeo, levantamento de dados por meio de pesquisas sobre a área de tradução, análise textual e análise comentada. Os resultados revelam que, ao realizar a tradução da língua escrita para a língua de sinais, poderemos nos deparar com diversos entraves, uma vez que nem todas as palavras da LP possuem um sinal representativo na Libras. Isso requer certas facetas que o permitam traduzir tais vocabulários. Por outro lado, é possível conhecer novos conceitos e ampliar o repertório lexical ao se debruçar na busca por sinais e estratégias que aproximem ao máximo possível a tradução do texto escrito, em LP, para a Libras.
\end{abstract}

Palavras-chave: Libras, Estratégias de Tradução, Tradução Intersemiótica.

\begin{abstract}
This essay aims at analyzing the lexical choices and strategies adopted to translate an article by Quadros and Xavier (2008) - written in Brazilian Portuguese $(L P)$, into the Brazilian Sign Language (Libras). This is a qualitative exploratory study, whose steps consists of the analysis of the corpus - the video, research on the area of translation, textual analysis, and commented analysis. In this way, the main types of translations in signal languages and the analysis of an intersemiotic translation are described, starting from a written source language (LP) to a visuospatial language (Libras). The discussion is grounded on the following authors: Jakobson (1975), Aubert (1994), Dolet (2004), among others. The results show that when translating written language into sign language, several obstacles may be found, since not all LP words have a representative sign in Libras. This requires, from the translator, certain facets that allow him/her to translate such vocabularies. On the other hand, it is possible to know new concepts and to expand the lexical repertoire by looking for signs and strategies that approximate as much as possible the translation of the written text, in LP, into Libras.
\end{abstract}

Keywords: Libras, Translation Strategies, Intersemiotic Translation.

Recebido em 27-12-2017 Aceito em 23-04-2018

\footnotetext{
${ }^{1}$ Professora de Libras da Universidade Estadual do Centro-Oeste, Campus de Irati/PR. Doutoranda do Programa de Pós-Graduação em Educação da Universidade Estadual de Ponta Grossa (UEPG). E-mail: lizi_st@yahoo.com.br.

2 Pós-graduação em Estudos da Tradução e Interpretação da Libras/Educação Especial e Inclusiva/Educação Matemática. Graduada em Letras Libras (UFSC) e Ciências - Matemática (UNIPAR). Proficiência em Tradução e Ensino da Libras. Tradutora e Intérprete de Libras da Secretaria de Estado da Educação, Paraná, Brasil. E-mail: josiane_joliveira@hotmail.com.
} 


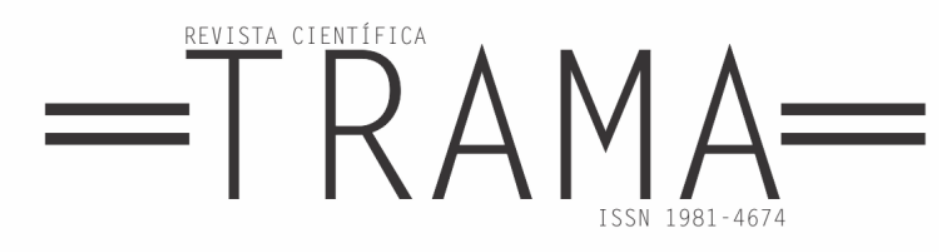

\section{$\mathbf{I}_{\text {NTRODUÇão }}$}

A atividade tradutória não é uma invenção da modernidade, ao contrário, ela sempre esteve presente e exerce um papel importante no desenvolvimento das civilizações. A atividade de tradução é, portanto, considerada necessária em várias questões sociais e históricas como, resolução de conflitos militares, negociações comerciais, enriquecimento cultural, situações diplomáticas entre outros.

É por meio da tradução que se abrem portas de acesso às informações, e surgem oportunidades de forma mais democrática de se obter um entendimento e de se fazer entender. Nesta pesquisa, utilizaremos o termo tradução em seu sentido amplo do ato de traduzir, de transferência de informações de uma língua a outra. Não iremos, aqui, nos aprofundar nas vertentes que diferenciam a nomenclatura do processo de tradução e de interpretação, porém, iremos abordá-las de forma sucinta.

Há vários tipos de tradução de acordo com diferentes autores. Dentre elas temos a tradução intersemiótica, na qual o processo tradutório parte de uma língua fonte escrita (Língua Portuguesa - LP) para uma língua visoespacial (Língua Brasileira de Sinais Libras).

Nesse panorama, o presente estudo tem como objetivo analisar as escolhas lexicais, bem como as estratégias adotadas por uma acadêmica do curso de Letras Libras da Universidade Federal de Santa Catarina (UFSC), em seu Trabalho de Conclusão de Curso (TCC), ao traduzir um artigo escrito, na Língua Portuguesa (LP), para a Língua Brasileira de Sinais (Libras). O referido texto corresponde a um artigo de Quadros e Xavier (2008).

Este ensaio é fruto de uma pesquisa qualitativa de caráter exploratório, que consistiu na análise do corpus - vídeo, levantamento de dados por meio de pesquisas sobre a área de tradução, análise textual, bem como análise comentada. Desta forma, serão descritos os principais tipos de tradução nas línguas de sinais e a análise de atuação de uma tradução intersemiótica, partindo de uma língua fonte escrita (LP) para uma língua visoespacial (Libras). Jakobson (1975), Aubert (1994), Dolet (2006), entre outros são autores que respaldam a discussão.

Os resultados revelam que, ao realizar a tradução da língua escrita para a língua de sinais, poderemos nos deparar com diversos entraves, uma vez que nem todas as palavras da LP possuem um sinal representativo na Libras. E isso requer do tradutor certas facetas que o permitam traduzir tais vocabulários. Por outro lado, é possível conhecer novos conceitos e ampliar o repertório lexical ao se debruçar na busca por sinais e estratégias que aproximem ao máximo possível a tradução do texto escrito, em LP, para a Libras.

A seguir, faremos uma breve explanação sobre o conteúdo do material base utilizado pela acadêmica em seu processo tradutório. Sugere-se aos interessados, para um completo entendimento, a leitura deste material em sua integra.

\section{Características do artigo TRADUZIDO}

O texto traduzido, cujo título é "Aspectos da tradução/encenação na língua de sinais brasileira para um ambiente virtual de ensino: práticas tradutórias do curso de Letras Libras", escrito por Ronice Müller de Quadros e Saulo Xavier de Souza (2008), faz parte das Séries de Pesquisas - Estudos Surdos III, organizadas por Ronice Müller de Quadros. O referido artigo contam trinta e nove páginas e está situado no Capítulo 8 , entre as páginas 170-209 da obra.

A tradução do texto, da Língua Português (língua fonte), para a Libras (língua alvo), foi realizado por meio do processo de tradução intermodal e intersimiótica/interlingual, as quais serão descritas mais abaixo. Esse processo de tradução ocorreu por meio de filmagens (vídeo-captura), em que o texto produzido em língua de sinais foi gravado e armazenado.

O conteúdo do material base apresenta algumas práticas de tradução realizadas entre tradutores/atores surdos do Curso de Letras Libras. Desta forma, os alunos têm 


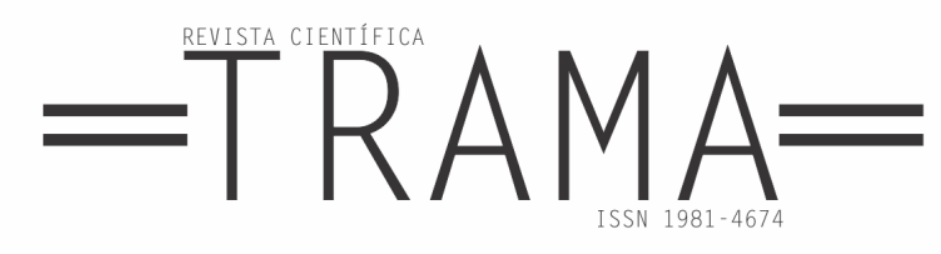

acesso aos textos, tanto na forma escrita como em Libras.

No texto, em LP, os autores divide o artigo em três momentos: o primeiro apresenta as técnicas de tradução na produção do material didático em Libras para os acadêmicos do curso de Letras Libras; no segundo, é feita a descrição do processo propriamente dito, como também as técnicas utilizadas na produção dos textos em sinais e no terceiro momento os autores sugerem possibilidades de pesquisas a fim da aplicação das técnicas desenvolvidas serem utilizadas em traduções especificas nos ambientes virtuais de ensino.

\section{Apontamentos teóricos}

Apresentaremos, a seguir, de forma sucinta, a função designada ao profissional tradutor e intérprete para facilitar a compreensão desse campo de estudo. As descrições foram realizadas com base nos estudos de Quadros (2004).

Intérprete: pessoa que interpreta de uma língua (língua fonte) para outra (língua alvo) o que foi dito.

Intérprete de língua de sinais: pessoa que interpreta de uma dada língua de sinais para outra língua, ou desta outra língua para uma determinada língua de sinais.

Tradutor: pessoa que traduz de uma língua para outra. Tecnicamente, tradução refere-se ao processo envolvendo pelo menos uma língua escrita. Assim, tradutor é aquele que traduz o texto escrito de uma língua para outra.

Tradutor/intérprete de língua de sinais: pessoa que traduz e interpreta a língua de sinais para a língua falada e vice-versa em quaisquer modalidades que se apresentar (oral ou escrita).

Maria Cristina Pereira (2008) pesquisadora e tradutora/intérprete de Libras define o processo de tradução e interpretação da seguinte forma:

[...] a tradução é o termo geral que se refere a transformar um texto a partir uma língua fonte, por meio de vocalização, escrita ou sinalização, em outra língua meta. A diferenciação é feita, em um nível posterior de especialização, quando se considera a modalidade da língua para qual está sendo transformado o texto. Se a língua meta estiver na modalidade escrita tratase de uma tradução; se estiver na modalidade vocal (também chamada de oral) ou sinalizada (presenciais ou de interação imediata), o termo utilizado é interpretação (PEREIRA, 2008, p. 2).

Ao tentarmos definir a palavra traduzir, percebemos que o seu conceito vai além do ato de transferir uma língua para outra. Guerini $(2008$, p. 2) considera que a palavra tradução em seu modo restrito - é uma operação de transferência linguística, em modo amplo - qualquer operação de transferência de códigos ou, inclusive dentro de códigos.

Jakobson (1975, p. 64-65) define a tradução em três tipos:

1) A tradução intralingual ou reformulação, que consiste na interpretação dos signos verbais por meio de outros signos da mesma língua. Independentemente de sua relevância cultural ou estética, a operação intralingual está presente sempre, em todos os tipos de texto (STEINER, 2005, p.53).

2) A tradução interlingual ou tradução propriamente dita, que consiste na interpretação dos signos verbais por meio de alguma outra língua.

De acordo com Aubert (1994, p. 44),

$\mathrm{Na}$ visão mais corriqueira da tradução interlingual, mudam os códigos linguísticos, mas, pressupõe-se, a realidade retratada no texto, o referente - frequente e simplesmente identificado com o conteúdo do texto - deve permanecer o mesmo; e uma das dificuldades da tradução será, então, encontrar na língua de chegada meios de expressão para um referente diverso daquele que o complexo língua/cultura de chegada usualmente exprime (AUBERT (1994, p. 44).

3) A tradução intersemiótica ou transmutação, que consiste na interpretação dos signos verbais por meio dos sistemas de signos não verbais.

Na tradução, da LP para a LS, a tradução interlingual não traduz a especificidade 


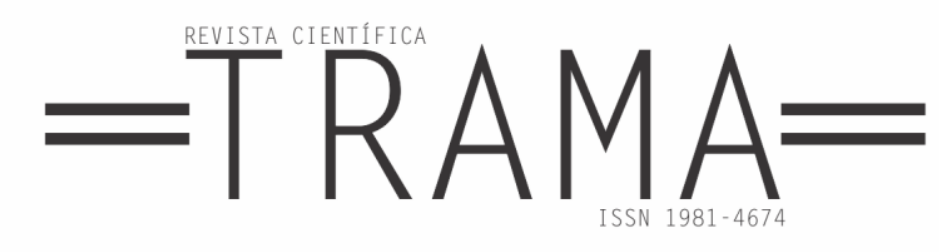

envolvida, pois estamos diante de línguas de diferentes modalidades, portanto intermodal (interlinguísticas). Já a tradução em que ocorre a transmutação de uma obra de um sistema de signos a outro, transferindo a forma e a tradução entre um sistema verbal e um não verbal, é definida como Tradução Intersemiótica.

Atualmente, o processo de tradução que envolve línguas de modalidades diferentes, como línguas orais e/ou escritas para línguas visuais/gestuais, pode ser realizado por meio do sistema Signwriting ${ }^{3}$, como também por um sistema de gravação em vídeo. Neste sentido, é necessário que o profissional (tradutor) domine as línguas envolvidas que diferem quanto a sua modalidade, sendo que a falta de conhecimento específico implica diretamente na compreensão do leitor.

Nesse panorama, $o$ ato de traduzir requer do tradutor alguns princípios importantes. Entre eles, Dolet (2006, p. 15-19) considera que:

a) $\mathrm{o}$ tradutor deve entender perfeitamente o sentido e a matéria do autor a ser traduzido; b) o tradutor deve conhecer, perfeitamente, a língua do autor que ele traduz, e que ele seja, igualmente, excelente na língua na qual se propõe a traduzir; c) o tradutor não deve traduzir palavra por palavra; d) o tradutor deve usar palavras de seu uso corrente; e) o tradutor deve observar a harmonia do discurso (DOLET, 2006, p.15-19).

Um dos grandes desafios do tradutor concentra-se na questão da fidelidade. A quem se deve ser fiel? Por meio de seus experimentos, Gile (1995) faz sugestões de possibilidades tradutórias, no qual apresenta um modelo de composição de um texto na língua-alvo. Traduzindo seu diagrama poderíamos realizar a leitura da seguinte forma: "um texto produzido na língua-alvo é composto de vários elementos, tais como: mensagem, bagagem de informação do emissor, informações induzidas linguisticamente conforme a língua-fonte e a língua-alvo, como também, as informações pessoais do tradutor". Gile (1995, p. 62) também considera pertinente a "explicitação" nas práticas tradutórias por tornar os textos-alvo mais claros.

Segundo Aubert (1994, p.76):

A diversidade é a própria justificativa, a razão de ser da tradução. Não fossem diversos os códigos, as culturas, os momentos históricos, os homens, não haveria motivo para traduzir. Mas, se não houvesse a tentativa de fidelidade, a busca sistemática e obstinada de atinar-ainda que em vão - com que o autor original "quis dizer" e de encontrar meios de expressão para essa intenção comunicativa suposta, também não haveria tradução, diálogo, intertextualidade, intersubjetividade, mas, tão-somente, discurso diversos, cruzados, desconexos, mutuamente incompatível (AUBERT, 1994, p. 76).

Mais adiante o autor postula que:

A fidelidade na tradução caracteriza-se, pois, pela conjuminação de um certo grau de diversidade com um certo grau de identidade; ela será, não por essencialidade, um compromisso (instável) entre essas duas tendências aparentemente antagônicas, atingindo a sua plenitude nesse compromisso e nessa instabilidade. (AUBERT, 1994, p. 76).

Desta forma, o que se caracteriza uma tradução fiel? Conforme mencionado por Ronai (1987, p. 23), "haverá muitas traduções boas, mas não a boa do original". Eco (2007), por sua vez, observa a impossibilidade da fidelidade porque, ao traduzirmos, não dizemos nunca a mesma coisa, mas quase a mesma coisa.

Aubert (1993, p.76) alega que é preciso haver não uma, mas duas fidelidades, com a mensagem em si e com o destinatário, isto é, quem vai ler a sua tradução. Afinal, a prática tradutória pode seguir rumos diferentes de acordo com o público que a irá consumir.

3 Criada em 1974 por Valerie Sutton o SignWriting é uma representação escrita das línguas de sinais. 


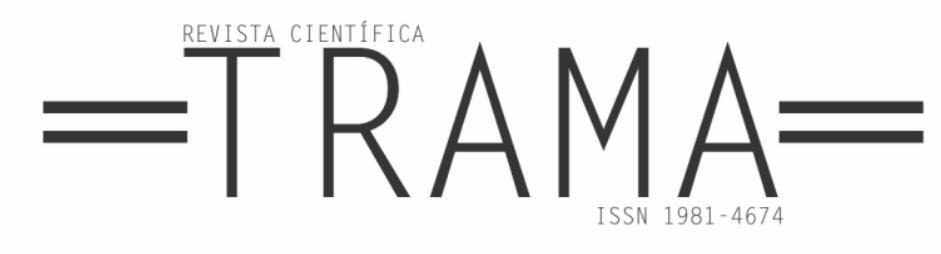

O tradutor também deverá realizar as análises quanto a seu ato tradutório, refletindo sobre as estratégias que utilizará para que o seu desempenho ocorra de forma fluente, de tal maneira que o leitor usuário de Libras possa se sentir satisfeito.

O tradutor e teórico da tradução ítaloamericano Lawrence Venuti (1995) apresenta em seu artigo "A invisibilidade do tradutor", as estratégias de domesticação e estrangeirização. $\mathrm{Na}$ tradução em que se utiliza a estratégia de domesticação observamos algumas adaptações ao comparar o texto original ao texto traduzido. Tais adaptações oportunizam uma leitura nos "moldes" da cultura da língua alvo, ou seja, é trazer para a cultura do país da língua de chegada, valores locais facilitando a compreensão do texto de forma confortável e prazerosa. "A tradução vai parecer natural, pois o ritmo, a fluência, as imagens e as marcas culturais e sociais são as da língua do leitor e não a do original; o autor e o tradutor ficam invisíveis na tradução" (SEGALA, 2010, p.46).

Ao oposto do que já foi descrito, a estratégia de estrangeirização propõe a permanência dos vestígios e acesso a língua original, o tradutor deixa todas as marcas rompendo os códigos culturais dominantes na língua-alvo. Partindo da análise de duas estratégias, Venuti (1995) percebe que em ambas ainda há imperfeições, mas que apresentam particularidades importantes, desta forma, o autor propõe a estratégia minorizante que confronta línguas e culturas diferentes respeitando suas especificidades. Ao realizar a tarefa de traduzir, Segala (2010, p. 50) adverte que o tradutor precisa:

[...] deixar marcas do texto original, ao mesmo tempo em que as adapta para o texto traduzido, sem, necessariamente, domesticá-las, ou seja, o leitor do texto traduzido percebe as marcas da sociedade, da cultura, da época e da língua em que o original foi traduzido, mas sente-se confortável, porque percebe esses vestígios em relação a sua

\footnotetext{
${ }^{4}$ Termo utilizado para identificar o tradutor que assume um papel de "ator" em seu momento de encenação, em que os textos escritos são filmados na versão em Libras.
}

própria sociedade, cultura, época e língua (SEGALA, 2010, p. 50).

Segala (2010) realiza comparações entre as estratégias levando em consideração as dificuldades que podem ocorrer na compreensão dos leitores surdos no processo de tradução em língua de sinais. O autor ressalta que há muitos surdos que tem dificuldade em entender o texto traduzido por desconhecimento da cultura, dos valores sociais e da língua original, considerando assim, a proposta minorizante sendo a estratégia mais adequada, em que o tradutor terá condições de fazer as adaptações necessárias, porém respeitando a cultura e língua fonte.

\section{Organização didática TRADUTÓRIA}

A tradutora/atriz ${ }^{4}$ apresenta alguns passos que servem de base para a estrutura, construção e produção do vídeo. Tentaremos, de forma sucinta, descrever o processo utilizado.

Após leitura e releitura do artigo a ser traduzido, a sistematização do conteúdo escrito foi organizada em forma de glosas 5 em uma tabela, sendo que: na primeira coluna inseriu-se o texto fonte (LP escrita); e na segunda coluna, o texto traduzido para a língua alvo (Libras).

As glosas foram organizadas por conclusão de ideias, contendo um ou mais parágrafos. De um lado, o texto na íntegra, do outro, uma adaptação de escrita utilizando o português a fim de obter um recurso visual, mas com a estrutura da língua de sinais.

A tradutora/atriz utilizou-se tanto dos recursos visuais (notebook e glosas) quanto dos recursos auditivos (gravação em áudio do texto) para que a mesma, não se limitasse a realizar apenas a leitura na disposição escrita, podendo, assim, comprometer a filmagem. Situação esta identificada no

${ }^{5}$ Representação do texto na estrutura da Libras com palavras em português -interlíngua escrita. (QUADROS e SOUZA, 2008). 


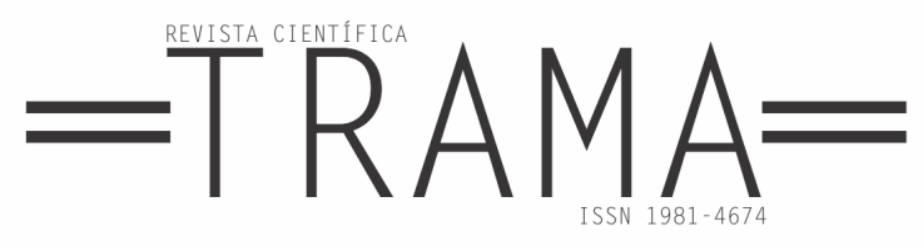

momento da revisão e edição do vídeo, no qual os movimentos dos olhos marcaram tal expressão de leitura.

Ao anteceder a sinalização do texto, algumas informações importantes, expostas na forma original, como imagens, tabelas, vocabulários desconhecidos para transição em sinais, exigiu da tradutora uma busca mais detalhada, sendo necessária a mediação e auxilio de surdos sinalizadores, tradutores e intérpretes de língua de sinais (TILS), dicionários trilíngue e um dos autores do artigo em análise.

Para o registro da tradução intersemiótica, utilizou-se os seguintes instrumentos: uma filmadora portátil digital; uma parede de fundo azul (revestida por TNT); um notebook para o acesso visual das glosas; um gravador para registrar em voz as glosas; uma pessoa para auxiliar na gravação e iniciar o áudio. A leitura foi realizada ora diretamente no computador, ora impressas em folhas de sulfite A4. Desta forma, a tradutora/atriz buscou uma referência visual, auditiva e linguística do que seria sinalizado, e concomitantemente, filmado.

Figura 1 - Imagem ilustrativa do uso de glosas reproduzidas no notebook

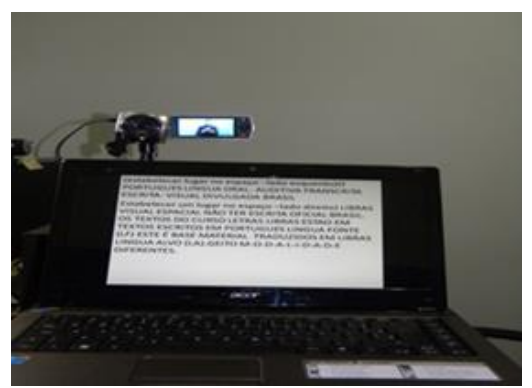

Fonte: acervo fotográfico dos pesquisadores

Figura 2 - Filmagem

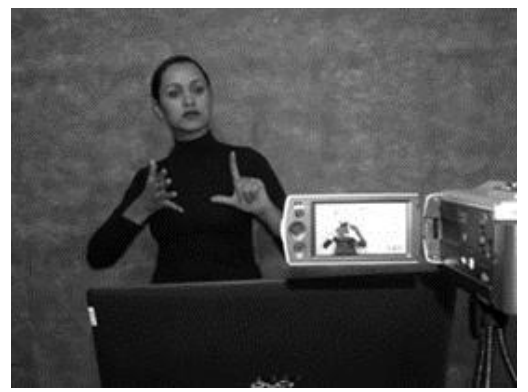

Fonte: acervo fotográfico dos pesquisadores
Após a captura da tradução em Libras, a tradutora contou com o apoio de um TILS, a fim de se obter uma segunda opinião sobre o trabalho realizado, verificando a necessidade ou não de refazer a gravação (na íntegra ou em partes).

Por ser um trabalho produzido em uma esfera tridimensional, sua estrutura não se deu por meio de páginas numeradas, visto que se tratava de uma produção de tradução intersemiótica, ou seja, uma tradução que corresponde a um determinado sistema de signos a outro, de um sistema verbal para um não verbal.

Para facilitar a refilmagem, caso pudesse ocorrer possíveis falhas no momento da gravação, optou-se por dividir a filmagem por sete blocos assim descritos:

Quadro 1 - Divisão da filmagem

\begin{tabular}{|c|c|c|}
\hline BLOCO & $\begin{array}{l}\text { DIVISÃO DE } \\
\text { CAPTURA }\end{array}$ & $\begin{array}{l}\text { TEMPO } \\
\text { APROX. }\end{array}$ \\
\hline Bloco 1 & $\begin{array}{l}\text { Apresentação do } \\
\text { capítulo, do tema, os } \\
\text { autores e nota de } \\
\text { rodapé. }\end{array}$ & 00:01:15 \\
\hline Bloco 2 & $\begin{array}{l}\text { Resumo e palavras- } \\
\text { chave }\end{array}$ & 00:03:00 \\
\hline Bloco 3 & Introdução & 00:08:40 \\
\hline Bloco 4 & $\begin{array}{l}\text { O desenvolvimento } \\
\text { contempla um total de } \\
\text { sete temas, entre título } \\
\text { e subtítulo }\end{array}$ & $00: 16: 12$ \\
\hline Bloco 5 & $\begin{array}{l}\text { Conclusão (palavras } \\
\text { finais) }\end{array}$ & 00:01;30 \\
\hline Bloco 6 & Agradecimentos & 00:00:30 \\
\hline Bloco 7 & Referências & 00:00:15 \\
\hline
\end{tabular}

Fonte: elaborado pelos pesquisadores

Outra estratégia adotada foi a padronização da cor da roupa usada pela sinalizante com opção de diferentes cores, com o objetivo de identificar no momento da tradução, as especificidades do texto da língua fonte, conforme segue:

Quadro 2 - Padronização da cor da roupa

\begin{tabular}{|c|c|}
\hline COR & UTILIZAÇÃO \\
\hline $\begin{array}{c}\text { Cor azul } \\
\text { marinho }\end{array}$ & $\begin{array}{c}\text { Foi utilizado praticamente em } \\
\text { todo texto traduzido }\end{array}$ \\
\hline Cor bege & Para "nota de rodapé" \\
\hline Cor vermelha & $\begin{array}{c}\text { Para citações diretas e } \\
\text { indiretas }\end{array}$ \\
\hline Cor verde & $\begin{array}{c}\text { Para palavras- chave (sinais } \\
\text { importantes) }\end{array}$ \\
\hline
\end{tabular}

Fonte: elaborado pelos pesquisadores 


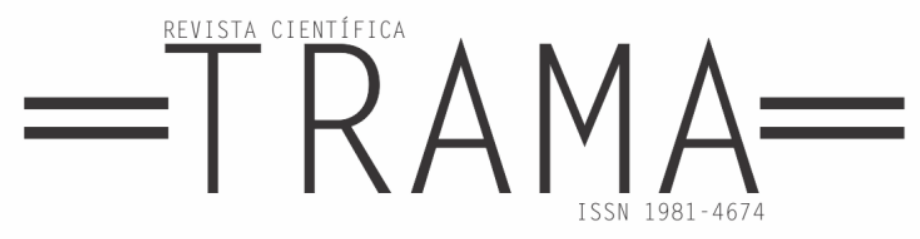

\section{Análise e discussão}

A seguir, apresentaremos algumas terminologias identificadas no texto. Sua criação baseia-se na pesquisa junto à TILS como também surdos sinalizadores. Essas escolhas justificam-se por não possuírem um sinal representativo na Libras e/ou pela necessidade de uma melhor escolha de acordo com o contexto apresentado. Este processo de escolhas caracteriza um dos passos para ato tradutório.

\section{Glossário}

\section{Quadro 3 - Glossário}

\begin{tabular}{|c|c|c|}
\hline PORTUGUÊS & $\begin{array}{l}\text { TRADUÇÃO/ } \\
\text { JUSTIFICATIVA }\end{array}$ & LIBRAS \\
\hline Técnicas & Estratégias & \\
\hline Palavras-chave & $\begin{array}{l}\text { "Sinais importantes". A } \\
\text { escolha para esta } \\
\text { representação baseou-se } \\
\text { no contexto abordado e } \\
\text { por se tratar de uma } \\
\text { modalidade diferente. }\end{array}$ & \\
\hline Impressão digital & $\begin{array}{c}\text { Neste caso representa a } \\
\text { presença do tradutor - } \\
\text { sequência de dois sinais: } \\
\text { sua marca, sua } \\
\text { identidade. }\end{array}$ & \\
\hline Neologismos & Sinais novos & \\
\hline Glosas & $\begin{array}{c}\text { Sinal específico utilizado } \\
\text { entre os tradutores/atores } \\
\text { da UFSC }\end{array}$ & \\
\hline
\end{tabular}




\section{$=$ TRAMA $=$}

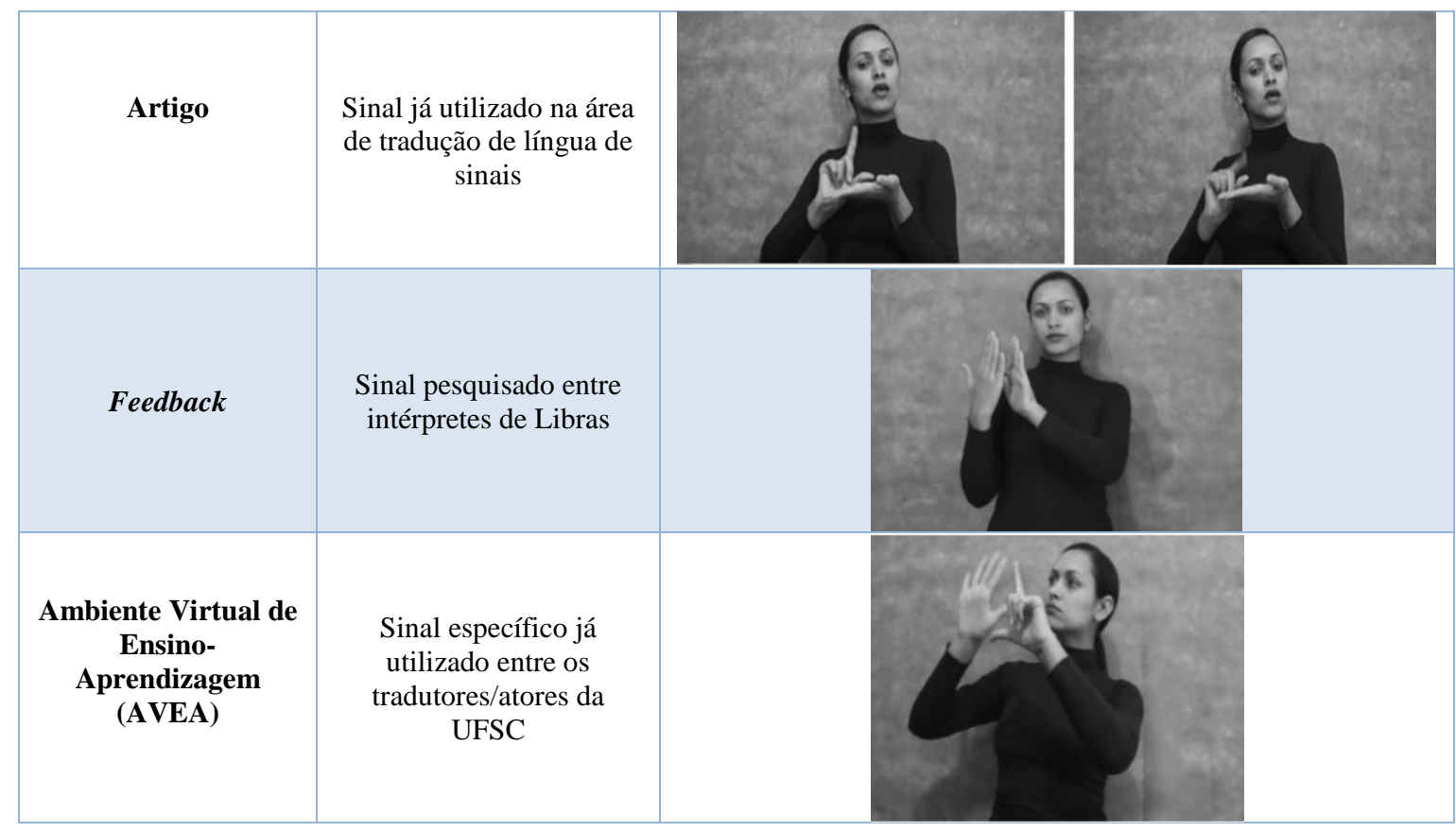

Fonte: elaborado pelos pesquisadores

A verificação de sinais e de terminologias possibilita ao tradutor fazer melhores escolhas no momento de sua atuação, lembrando que ao revisar a filmagem, dependendo da situação, das escolhas e/ou desenvoltura, o tradutor/ator deverá refazer a filmagem na íntegra (SOUZA, 2008).

Realizar o processo de tradução de uma Língua Fonte (LF) em português escrito para uma Língua Alvo (LA), neste caso a Libras, não é uma tarefa muito fácil, pois além de apresentarem modalidades diferentes, é necessário observar se os leitores irão compreender as informações traduzidas, por isso os tradutores/ intérpretes como também tradutores/atores utilizam em suas traduções estratégias adaptando a LF para LA. Segala (2010) destaca algumas estratégias de tradução categorizadas por Venuti (1995), sendo: a) Estratégia de domesticação. b) Estratégias de estrangeirização. c) Projeto minorizante.

A preocupação e as escolhas das estratégias utilizadas indicam para qual público de leitores estamos traduzindo, neste caso, são representados por formandos em nível superior, professores, pesquisadores em Libras e educação de surdos, professores surdos e ouvintes como também tradutores/intérpretes de Libras.
No processo de tradução foram contempladas não uma, mas diferentes estratégias com o propósito de tornar o mais natural possível o processo tradutório. Desta forma, a tradutora/atriz fez uso de transliteração, neologismo, paráfrase, permanência ou camuflagem de marcas da língua original entre outros.

\section{Processo tradutório}

A estratégia de tradução utilizada para a identificação do capítulo e tema foi disponibilizada em forma de legenda. Desta forma, os nomes dos autores, Ronice Muller Quadros e Saulo Xavier de Souza, foram representados utilizando o português escrito (digitalizados) e em sequência identificados pelos sinais correspondentes, como também a disponibilização de suas imagens (fotos). Para este contexto, foi utilizada a cor azul marinho.

Quanto às notas de rodapé, optou-se pelo uso de uma blusa com cor diferente do texto geral, visando reforçar a organização textual e suas especificações. Ao terminar a identificação de cada um isoladamente, e em função da preocupação de identificar a titulação dos autores do texto, foi inserido o vídeo com a sinalização da nota de rodapé, 


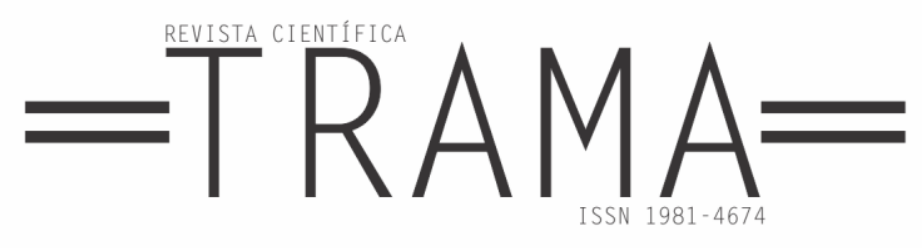

no qual está caracterizado o uso da blusa de cor bege. Nos textos das línguas orais a nota de rodapé fica abaixo do texto no lado inferior da folha. Já na Libras houve a preocupação de fazer adaptações, levando em consideração que o leitor necessita da informação de forma "imediata", incorporadas no texto parar fazer a correspondência do que foi sinalizado. Desta forma, percebe-se claramente a diferença de modalidade.

A construção discursiva na Língua de Sinais Brasileira apresenta uma estratégia muito recorrente: o uso de exemplos para explicar conceitos. $\mathrm{Na}$ construção discursiva do Português, isso não é muito comum. Mesmo assim, os textos na Língua de Sinais passaram a integrar algumas explicações, ainda que essas não estivessem explicitadas na LF, como se fossem "notas de rodapé" do tradutor incorporadas no texto na Língua de Sinais. Isso poderia ser um link dentro do texto escrito, uma vez que estamos lidando com um ambiente de ensino virtual, no entanto, ainda não encontramos uma solução para conectar isso tudo dentro do texto sinalizado. (QUADROS; SOUZA, 2008, p. 184).

As expressões não manuais exercem um papel importante, pois estas fazem parte da estrutura gramatical da língua de sinais. No processo tradutório, foram destacadas: marcação de concordância gramatical, marcação associada ao foco, marcação de negativas, marcação de tópicos e marcação de interrogativas.

Como critério, a tradutora/atriz, no momento da transliteração, realizou, primeiramente, a digitalização e na sequência a sinalização correspondente.

No artigo foram identificadas marcas textuais como as abreviaturas, siglas, nestas, foram utilizadas a estratégia de soletração, sinal-soletrar as iniciais que formam a palavra. Por exemplo: ASL, LSF, LA, LF,

\footnotetext{
${ }^{6}$ Dêixis refere-se a uma palavra grega que significa 'apontar' ou 'indicar'. Desta forma, 'a função dêitica em Línguas de Sinais, como na Língua de Sinais Brasileira e na ASL é marcada
}

podendo estar acompanhado ou não do sinal correspondente.

O uso de aspas duplas (" ") também segue um critério próprio. A realização do sinal ocorre respeitando uma delimitação no espaço, movimentos curtos em frente ao peito- espaço neutro, digitalizando dentro desse espaço.

Todos os títulos e subtítulos foram editados e apresentados em forma de legenda em português. Em relação aos numerais e cardinais a exemplo dos decretos e leis, depois de sinalizados houve o reforço, também com legenda editados no vídeo.

No texto fonte é apresentado o mapa do Brasil, a fim de identificar os Estados polos do Curso de Letras Libras. A tradução, para esse contexto, foi utilizada o dêixis ${ }^{6}$, um sinal específico que faz a correspondência dos referentes no espaço, identificando cada estado citado.

Quanto às marcas no texto, como por exemplo, as palavras destacadas em itálico, a tradutor/atriz optou por posicionar as mãos verticais abertas, palma a palma, (a digitalização é realizada dentro deste espaço), em frente ao peito e em seguida incliná-las para o lado direito. Assim, os leitores poderiam identificar tal diferenciação.

No uso de parênteses (sinal já padronizado), além da sinalização, realizou o reforço com a expressão não manual, pela marcação de tópico.

O uso da datilologia ou transliteração, conforme menciona Segala e Souza (2008), é uma das estratégias de tradução que pode ser utilizada pelos tradutores/atores, desta forma é identificada em situações como, por exemplo: M-O-D-A-L-I-D-A-D-E, I-M-PR-E-S-S-A-O D-I-G-I-T-A-L, R-U-I-D-OS, E-X-P-L-I-C-I-T-A-Ç-Ã-O- e T-R-A-NS-L-I-T-E-R-A-Ç-Ã-O. Essa estratégia também foi utilizada em palavras e/ou frases em língua estrangeira.

Para representar itens quantificadores, a opção foi fazer a relação com a configuração

através de apontação propriamente dita. Os referentes são introduzidos no espaço à frente do sinalizador, através da apontação em diferentes locais" (QUADROS; KARNOPP; 2004 p.112). 


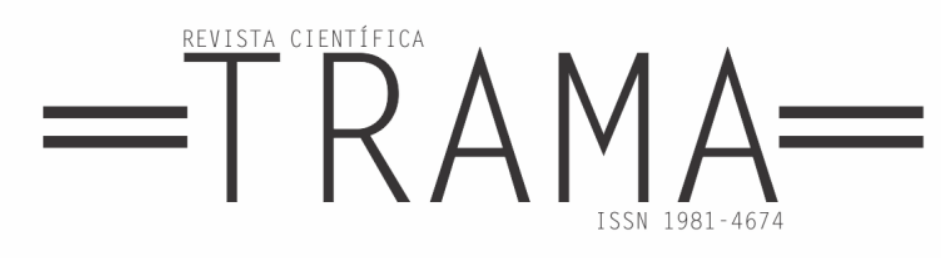

de mão $(\mathrm{CM})^{7}$. Por exemplo, para nomear cada fato, e neste caso, três situações distintas, utilizou-se a $\mathrm{CM}$ em $\mathrm{W}$, palma para trás, na posição horizontal, obedecendo à ordem sequencial de apontamento para os três dedos selecionados.

As tabelas e quadros, presentes no texto fonte, permaneceram em sua forma originais apresentados por cópia de sua imagem no vídeo.

Por fim, o último tópico do artigo corresponde às referências, as quais foram apresentadas em forma de créditos, em português escrito editadas na filmagem.

Ao concluir a tradução, a tradutora/atriz realiza uma análise da própria tradução. Nesta etapa, ela estabelece uma comparação da proposta inicial ao resultado após a captura em vídeo, assim pode levantar as diferenças tradutórias (mudança de léxicos, utilização ou não de paráfrase, etc.) que ocorreram durante $\mathrm{o}$ processo até sua conclusão.

\section{Nossas conclusões}

No contexto atual, constatamos inúmeros avanços da comunidade surda brasileira em prol da acessibilidade e inclusão social. E o TILS representa uma dessas conquistas, refletindo, por meio de sua voz, os anseios do sujeito surdo. O curso de Letra Libras, em nível de Bacharelado e Licenciatura vem ao encontro da legislação, a qual prevê, aos surdos, o direito de se comunicarem em língua de sinais, e tem como objetivo formar profissionais capacitados em nível de graduação.

Verificamos por meio da análise da sinalização, ou seja, da tradução desenvolvida pela acadêmica, que há uma incansável busca por estratégias e metodologias mais adequadas a serem utilizadas no ato tradutório. Evidência também uma grande conquista e valorização da língua de sinais, pois o TCC, proposto aos acadêmicos do Curso do Letras Libras, apresenta-se com um formato totalmente diferente dos habituais.

${ }^{7}$ Configuração de Mão (CM): Forma que a mão se articula para execução de um sinal, sendo este,

Esse modelo pode contribuir para um novo campo de pesquisa, pois oferece novas alternativas de avalição no contexto educacional de surdos, principalmente do Ensino Superior. Além disso, fortalece ainda mais a credibilidade e status da língua de sinais como uma possibilidade de os surdos poderem expressar seus conhecimentos por meio dela.

Podemos constatar, também, que a profissão de tradutor exige um profundo conhecimento na área, tanto da língua fonte como da língua alvo, bem como uma dedicação constante para acompanhar a sua evolução. Desta forma, o tradutor exerce um "poder" sobre as línguas e sobre os leitores dessa língua, porém correndo o risco de se perder diante de tal autonomia quando deixa de transmitir de forma clara e precisa as informações, e de manter o nível de "fidelidade" junto ao autor e ao leitor, bem como, com sua própria consciência.

\section{Referências}

AUBERT, F.H. A (in) fidelidade da tradução: servidões e autonomia do tradutor/ Francis Henrik Aubert. 2. ed. Campinas, SP: Editora da UNICAMP,1994.

BRASIL. Decreto $\mathrm{n}^{\circ} 5.626$, de 22 de dezembro de 2005. Regulamenta a Lei ${ }^{\circ}$ 10.436, de 24 de abril de 2002, que dispõe sobre a Língua Brasileira de Sinais - Libras, e o art. 18 da Lei no 10.098, de 19 de dezembro de 2000. In: Diário Oficial da União de 23 de dez. 2005, Brasília.

DOLET, É. Como traduzir bem de uma língua a outra. Tradução de Nícia Adan Bonatti e Marc Goldstein. In: FURLAN, Mauri. (Org.). Clássicos da Teoria da Tradução. Florianópolis: UFSC, Núcleo de Tradução, v.4, 2006. p. 198-205. Antologia Bilíngue.

ECO, U. Quase a mesma coisa. Experiências de Tradução. Rio de Janeiro/

um dos parâmetros na formação de palavras na Libras. 


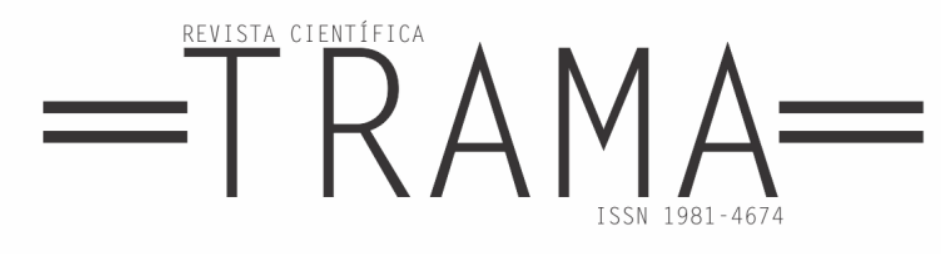

São Paulo: Record, 2007. Tradução de Eliana Aguiar.

GESSER, A. Tradução e interpretação de LIBRAS II. Florianópolis - UFSC, 2011.

GILE, D. Basic Concepts and Models for Interpreter and Translator Training. Amsterdam/Philadelphia: John Benjamins, 1995.

GUERINI, A. Introdução aos Estudos da Tradução. Florianópolis - UFSC, 2008.

HEIDERMANN, W. Estudos da Tradução III. Florianópolis, 2009.

JAKOBSON, R. Linguística e comunicação. Trad. Izidoro Blikstein e José Paulo Paes. 8. ed. São Paulo: Cultrix, 1975

JUNIOR, L. A. B.; VASCONCELLOS, M. L: Estudos da Tradução I. FlorianópolisUFSC, 2008.

MASUTTI, M. L.; PATERNO, U. Tradução e Interpretação de LIBRAS. Florianópolis - UFSC, 2011.

PEREIRA, M. C. P. Interpretação interligue: as especificidades da interpretação de língua de sinais. In Cadernos de Tradução XXI, 2008/1. Florianópolis, Brasil.

QUADROS, R. M.; SOUZA, S, X. Aspectos da tradução/encenação na Língua de Sinais Brasileira para um ambiente virtual de ensino: práticas tradutórias do curso de Letras Libras. In: QUADROS, R. M. (Org.) Estudos Surdos III. Petrópolis, RJ: Arara Azul, 2008.

QUADROS, R. M. O tradutor e interprete de língua brasileira de sinais e língua portuguesa. Secretaria de Educação Especial. Programa Nacional de Apoio à Educação de surdos, Brasília: MEC, SSEP, 2004

QUADROS, R. M.; KARNOPP, L. Língua de sinais brasileira: estudos linguísticos. ArtMed: Porto Alegre, 2004.
RONAI, P. Escola de tradutores. Rio de Janeiro. Nova Fronteira, 1987.

SEGALA, R. Tradução Intermodal e intersemiótica/Interlingual: Português Brasileiro escrito para a língua de Sinais. 2010. 74f. Dissertação (Mestrado em Estudos da Tradução) - Universidade Federal de Santa Catarina, Florianópolis, 2010

STEINER, G. Depois de Babel: questões de linguagem e tradução. Curitiba: Editora UTFPR, 2005.

SOUZA, S. X. Performances de Tradução para a Língua Brasileira de Sinais Observadas no Curso de Letras-Libras. 174f. DissertaçãoMestrado em Estudos da Tradução, Universidade federal de Santa Catarina, Florianópolis, 2010.

VENUTI, L. A invisibilidade do tradutor. In: Palavra 3. (1995) 111-134. Tradução de Carolina Alfaro. Rio de Janeiro, 1995. Tradução de: The translator invisibility: In: Criticism. V XXXVIII, n.2, Spring 1986, Wayne state UP, p. 179-212.

VENUTI, L. Escândalos da tradução: por uma ética da diferença. Trad. Laureano Pelegrin, Lucinéia M. Villela, Marileide D. Esqueda e Valéria Biondo. Bauru, SP: EDUSC, 2002. 